\title{
A Mathematical Study of Effect of Humidity on Human Skin Temperature at Warm Environment
}

\author{
Shiva Hari Subedi \\ Department of Applied Sciences, Thapathali Campus, Institute of Engineering, Tribhuvan University, Nepal \\ Corresponding Author: ssubedi@tcioe.edu.np
}

Received: 2020-12-10

Revised: 2021-03-12

Accepted: 2021-03-13

\begin{abstract}
:
The ability of the human body to regulate its heat exchange depends on various environmental factors together with its ability to exchange heat in in-vivo tissue. The environmental factor humidity plays a crucial role in heat regulation within the human body. The heat regulation within in-vivo tissue constitutes temperature regulation in the layers of the dermal part to maintain body core temperature constant. The purpose of this article is to develop a mathematical model to study the effect of humidity on temperature regulation within the human body. The model has been developed for one dimensional steady state flow of heat in human dermal parts with appropriate boundary conditions containing the factors of effect of humidity. Matlab program has been used to simulate the model and obtain numerical results with graphs.
\end{abstract}

Keywords: Thermoregulation, Pennes' bio-heat transfer equation, human dermal parts, humidity, evaporation rate, finite element method

\section{Introduction}

The human body, complicated in structure, has to acclimate itself to thermal environmental change within limits as an automatic machine, by thermoregulation which provides thermal equilibrium of the body by heat transfer in biological tissues called bio-heat transfer so that the body core temperature is maintained almost at a constant temperature of $98.6^{\circ} \mathrm{F}$ or $37^{\circ} \mathrm{C}$.

The skin and subcutaneous tissue called dermal layers of the body, is the major organ that controls heat and moisture flow to and from the surrounding environment. Heat transfer within the layers of the skin of the human body is studied under the command of heat transfer partial differential equation with boundary conditions. The outer boundary condition involves sweat evaporation term which depends on humidity too. This differential equation involves various components and depends on a large number of parameters.

\subsection{Human thermoregulation}

Core temperature, also called core body temperature, is the operating temperature of an organism, specifically in deep structures of the body such as the liver, in comparison to temperatures of peripheral tissues. Core temperature is normally maintained within a narrow range so that essential enzymatic reactions can occur. Significant core temperature elevation (hyperthermia) or depression (hypothermia) that is prolonged for more than a brief period of time is incompatible with human life. Thermoregulation is the process that allows the human body to maintain its core internal temperature. The state of having an even internal temperature is called homeostasis. All thermoregulation mechanisms are designed to return the body to homeostasis [1]. For a human, the healthy and safe core temperature varies within a very narrow bounds around $37^{\circ} \mathrm{C}$. Within a few degrees of that range, human may experience signs related to body temperature changes and feel thermal uncomforted. Temperature elevation up to $41^{\circ} \mathrm{C}$ and depression up to $32^{\circ} \mathrm{C}$ are of medical emergencies $[2,3,4]$. So the core temperature of the body, at different environmental conditions, should be maintained around $37^{\circ} \mathrm{C}$ by the function of the thermoregulatory system which involves heat gain and heat loss mechanisms between the body and environment. Thermoregulation mechanism for heat 
gain or thermal input to a body includes conduction, convection, radiation and metabolism. Whereas mechanism for heat loss or thermal output from the body includes conduction, convection, radiation and evaporation. The human dermal part, generally divided into three layers: epidermis, dermis, subcutaneous tissue plays the main role in human thermoregulation.

\subsection{Humidity and its effects}

The atmospheric layer above the surface of the earth includes air as mixture of gases, dust particles and water vapors. The amount of water vapors in the air mixture makes the climate dry or moist. Humidity is the amount of water vapor in a given space of the atmosphere. The measurement of the humidity of air can be described in various patterns.

Absolute Humidity $\left(\mathrm{Kg} / \mathrm{m}^{3}\right)$ is the density of water vapor per unit volume of air. Specific Humidity $(\mathrm{Kg} / \mathrm{Kg})$ is the weight of water vapor per unit weight of dry air. Relative Humidity [RH] (\%) is the ratio of the actual vapor pressure of the air-vapor mixture to the pressure of saturated water vapor at the same dry-bulb temperature times 100. RH depends on temperature and the pressure of the system of interest. It requires less water vapor to attain high $\mathrm{RH}$ at low temperature. More water vapor is required to attain high in warm or hot air.

The thermal effect of humidity on the human comfort is small, that is, comfort is maintained over a wide range of humidity. The body feels no discomfort at RH $20 \%$ $50 \%$ in winter and the tolerance range extends up to $60 \% \mathrm{RH}$ in summer. Above that with temperature $75^{\circ} \mathrm{F}$, the skin feels sweaty. In hot summer weather, high humidity reduces the rate of heat loss as it slows down the rate of evaporation. So body temperature tends to rise and human feels more temperature than actual air temperature. Such type of phenomena can be described by 'Heat Index' [5].

High RH disturbs the air to absorb the sweat from the skin which results more sweating so that body feels hot and sticky. When sweating can't cool down the body, core temperature begins to rise resulting in overheating, commonly known as heat exhaustion which leads to dehydration and chemical imbalances within the body. On the other hand low relative humidity may cause body temperature falling affecting the skin and respiratory system.

High humidity in summer can contribute to the growth of mold, dust mites, and fungus, making it particularly dangerous for people with asthma and allergies. Low humidity in winter with dry air can lead to dry skin, irritated sinuses and throat, and itchy eyes. It may increase the risk of cold, flu, and other infections. Further, in low humidity, certain virus such as flu may be able to survive larger [6]. Harper [7] reported that the survival rate of the influenza virus is only $3-5 \%$ after 6 hours in an environment of $20.5-24^{\circ} \mathrm{C}$ and $50 \%$ $\mathrm{RH}$ and above, but this rate increased to $66 \%$ under an environment of $20 \% \mathrm{RH}$. The influenza virus in the air loses infectivity in an environment with $50 \% \mathrm{RH}$ and above, but its survival time is prolonged in an environment with an RH below 50\% [8].

Some researcher reported that there is a seasonal factor in the rate of influenza infection, with respiratory infection prevalent especially in winter. This explains the long survival rate of the organism in environments with low humidity in winter, and the inflammation of the nasal and pharngolaryngeal mucosa caused by cold air inhalation makes it easier for these mucosa to be infiltrated by the organism. Therefore, in an environment with an RH below $10 \%$, it is fairly easy to catch a respiratory infection caused by an influenza virus in the air due to the fact that dryness of the nasal mucocilia compromises the defense mechanism [9]. Recent researches indicate that humidity is a consistent climatic factor contributing to SARS-CoV-2 transmission [10] and dry air affects immunity, viral spread of covid-19 [11]. Nevertheless, hospitals must carefully control humidity since the level of bacteria propagation is lowest between 50 and 55 percent RH [12].

\subsection{Sweating}

Sweat is liquid made by the skin when the body is hot. Sweat is made in sweat glands under the surface of the skin, and it comes out of tiny pores in the skin. sweat is mostly water, but it also contains some minerals, lactate and urea. Main purpose of sweat secretion is to cool the body suffering from overheating by evaporation as sweat takes the heat from the body when it evaporates. Sweat also helps to remove waste from the body. The amount of sweat production depends upon environmental conditions, human states of emotion and physical activity. The average person has over 4 millions sweat glands distributed over the entire body, except for the lips, nipple and external genital organs, and hence maximum sweat rates of an adult can be up 
to $10-15$ litres/day [13].

\subsection{Finite element method}

The finite element method $[14,15,16,17]$ is a powerful numerical technique that gives approximate solutions to differential equations that model field problem arising in physics and engineering. The finite element method requires a problem defined in geometrical space (or domain), to be divided into a finite number of smaller regions (elements). In the finite elements, each subdivision is unique and need not to be orthogonal as in finite difference methods. In one dimension the elements are lines, in two dimensions the elements are triangles or quadrilaterals while in three dimensions the elements are tetrahedral or prisms. The elements are interconnected at specified joints called nodes. Over each finite elements, the unknown field variables (e.g. temperature, velocity, pressure) are approximated using known functions; these functions can be linear or higher-order polynomial expansions in terms of the geometrical locations(nodes) used to define the finite element shape. The governing equations in the finite element method are integrated over each finite element and the contributions summed ("assembled") over the entire problem domain. As a consequence of this procedure, a set of finite linear equations is obtained in terms of the set of unknown parameters over the elements. Solutions of these equations are achieved using linear algebra techniques. Detailed information of theoretical development of the finite element method procedure can be easily and directly used to develop computer programming language such as Matlab $[18,19,20,21]$.

\section{Modal development and solution technique}

This section deals with the model formulation of one dimensional unsteady state temperature distribution in human dermal part. The model is generated from the Pennes' bio heat equation and the corresponding outer boundary condition in which the evaporative heat loss term is taken as an appropriate function of relative humidity and vapor pressure. The model gives generalization of tissue temperature as the function of depth of the skin measured perpendicularly from the outer surface. Variational Finite element method with Crank-Nicholson scheme is used to calculate the temperature distribution in three layers of the dermis.

\subsection{Evaporative heat loss}

Evaporation, a principal cooling mechanism in human thermo-regulation, is the process of loosing heat energy through the conversion of water to gas. Since heat loss by radiation and heat loss by convection alone are not able to maintain adequate homeostasis at high environmental temperature or during strenuous physical activity, evaporative heat loss is necessary for thermal balance. Water absorbs a great deal of heat energy before vaporisation, so its evaporation from the body surface removes large amount of body heat. The water lost by evaporation reaches the skin surface by diffusion and by neuron-activated sweat glands. At temperature above $36^{\circ} \mathrm{C}$ or so, heat loss occurs by evaporation only. In addition to this the surrounding air must be relatively dry in order for heat loss by evaporation. Humid and warm air effectively try restrict evaporation. But at any atmospheric temperature below skin temperature, the body can loss heat by evaporation, even if the environment is $100 \%$ humid [22].

In human body, evaporative heat losses under normal condition can occur by mainly three mechanisms [23]; by diffusion of water through the skin, by sweat secretion, and by evaporation of water into inspired air.

\subsubsection{Formulation for evaporative heat loss $[24,23,25,26,27,28]$}

(i) Vapor pressure of water at skin temperature: $P_{s}=1.92 T_{s}-25.3 \quad(m m H g)^{*}$

(ii) Partial vapor pressure of water in ambient air:

$$
P_{a}=P_{v} \times(R H \%) \quad(m m H g)
$$

(iii) Rate of evaporative heat loss by diffusion:

$$
Q_{d}=\frac{4184}{3600} \times 0.35\left(P_{s}-P_{a}\right) \quad\left(W / m^{2}\right)^{*}
$$

(iv) Rate of evaporative heat loss by sweating:

$$
Q_{s}=\frac{4184}{3600} \times K_{e}\left(P_{s}-P_{a}\right) \quad\left(W / m^{2}\right)
$$

Here $T_{S}$ be skin temperature such that $\left(27^{\circ} \mathrm{C}<T_{s}<37^{\circ} \mathrm{C}\right)$ and $P_{v}$ be saturated vapor pressure at air temperature $(\mathrm{mmHg})$.

$K_{e}$ be coefficient for evaporation $\left(\mathrm{Kcal} / \mathrm{m}^{2} \mathrm{hrmmHg}\right.$ ) determined experimentally by several investigators.

Thus, total heat loss rate per unit area (neglecting evaporation into inspired air) is

$Q_{E}=Q_{d}+Q_{s}=\frac{4184}{3600}\left(P_{s}-P_{a}\right)\left(0.35+K_{e}\right)=K\left(P_{s}-P_{a}\right)$

where, $K=\frac{4184}{3600}\left(0.35+K_{e}\right)$. 
Therefore,

$Q_{E}=L E=K\left[1.92 \times T_{s}-25.3-P_{v} \times \frac{R H}{100}\right] \quad\left(W / m^{2}\right)$

which is equivalent to

$$
\begin{array}{r}
Q_{E}=L E=\frac{6 K}{4189}\left[1.92 \times T_{s}-25.3-P_{v} \times \frac{R H}{100}\right] \\
\left(\mathrm{cal} / \mathrm{mincm}^{2}\right)
\end{array}
$$

Where,

$\mathrm{L}=$ latent heat of evaporation $(\mathrm{cal} / \mathrm{gm})$;

$\mathrm{E}=$ rate of evaporation $\left(\mathrm{gm} / \mathrm{min} \mathrm{cm}^{2}\right)$.

[* imbalances of units in RHS and LHS are due to scale out of the constants

for convenience.]

\subsection{Model formulations}

Governing Equation: Pennes' bio heat equation: The bioheat transfer equation for temperature distribution in the dermal part of a human in rest mainly consists of three components: conduction through tissue (diffusion of heat), blood perfusion (blood flow in the blood vessels) and metabolic heat generation. Thus the rate of total heat $\mathrm{Q}$ in tissue medium with respect to time $t$ is given as [29]:

$$
\frac{\partial Q}{\partial t}=\left(\frac{\partial Q}{\partial t}\right)_{D f}+\left(\frac{\partial Q}{\partial t}\right)_{P f}+\left(\frac{\partial Q}{\partial t}\right)_{M b}
$$

Where,

$Q=$ total heat flow per unit volume of tissue element $\left(\right.$ cal. $\left.\mathrm{cm}^{-3}\right)$,

$\frac{\partial Q}{\partial t}=$ the rate of total heat exchange per unit volume of

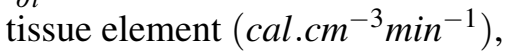

and terms with different suffices on the right side indicates the rate of heat exchange due to diffusion (Df), perfusion (Pf) and metabolism (Mb) respectively.

Formulating heat exchange due to diffusion by using Fourier's Law of conduction, due to perfusion by using Fick's law of perfusion and assuming metabolism term as $\mathrm{S}$, we get, from equation 2 ,

$$
\frac{\partial Q}{\partial t}=\nabla \cdot(K \nabla T)+\rho_{b} c_{b} w_{b}\left(T_{A}-T\right)+S
$$

Writing $\partial Q=\rho v c \partial T$ (here $\mathrm{Q}$ is heat flow per unit volume so $v=1)$ and $\rho_{b} c_{b} w_{b}=m_{b} c_{b}=M$

$$
\rho c \frac{\partial T}{\partial t}=\nabla \cdot(K \nabla T)+M\left(T_{A}-T\right)+S
$$

where,

$T=$ the temperature of tissue element at time $\mathrm{t}$ at a distance $\mathrm{x}$ measured from the outer surface of skin perpendicularly into the tissue element $\left({ }^{\circ} \mathrm{C}\right)$,

$\rho=$ tissue density $\left(\mathrm{gm} / \mathrm{cm}^{3}\right)$,

$\mathrm{K}=$ tissue thermal conductivity $\left(\mathrm{cal} / \mathrm{cm} \min { }^{\circ} \mathrm{C}\right)$,

$\mathrm{c}=$ tissue specific heat capacity $\left(\mathrm{cal} / \mathrm{gm}^{\circ} \mathrm{C}\right)$,

$m_{b}=$ blood mass flow rate $\left(\mathrm{gm} / \mathrm{cm}^{3} \mathrm{~min}\right)$,

$c_{b}=$ blood specific heat capacity $\left(\mathrm{cal} / \mathrm{gm}^{\circ} \mathrm{C}\right)$,

$\rho_{b}=$ blood density $\left(\mathrm{gm} / \mathrm{cm}^{3}\right)$,

$w_{b}=$ blood perfusion rate $\left(\mathrm{gm} / \operatorname{min~}^{3}\right)$,

$T_{A}=$ arterial blood temperature $\left({ }^{\circ} \mathrm{C}\right)$,

$\mathrm{S}=$ metabolic heat generation rate $\left(\mathrm{cal} / \mathrm{cm}^{3} . \mathrm{min}\right)$,

$M=m_{b} c_{b}=\left(\mathrm{cal} / \mathrm{cm}^{3} . \mathrm{min}\right)$,

$\nabla T=i \frac{\partial T}{\partial x}$.

Equation 3 is the second order partial differential equation, a modification of universally famous as Pennes' Bioheat Equation [30] introduced by Harry H. Pennes' in 1948.

\subsection{Finite element discretization}

The human dermal part is divided into three natural layers - epidermis, dermis and subcutaneous tissue. Schematic diagram of temperature distribution model in three layers is as shown in figure 1 .

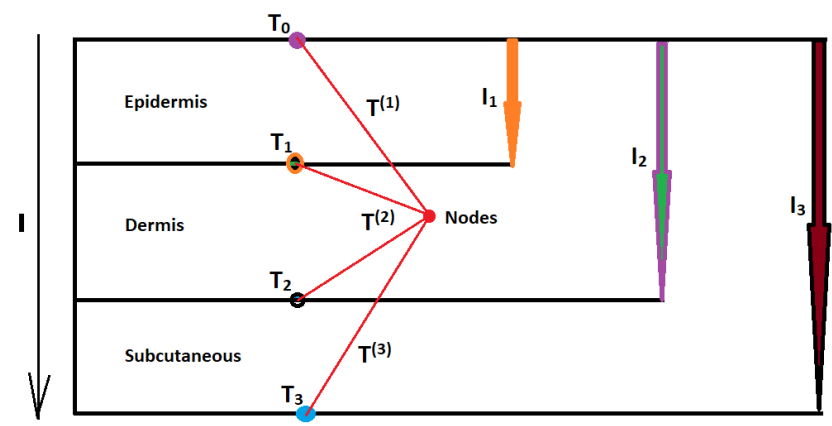

Figure 1: Finite Element Discretization of Layers of Skin

Here,

$l_{1}, l_{2}-l_{1}$ and $l_{3}-l_{2}$ are thickness of epidermis, dermis and subcutaneous tissue respectively

$T^{(i)}(x)=T^{(i)}=$ temperature function for $l_{i-1}<x<l_{i}$ with $l_{0}=0 ; i=1,2,3$

$T_{i}=$ nodal temperature at $x=l_{i}$ with $l_{0}=0$ (outer surface); $i=0,1,2,3$

The temperature distribution function $T^{(i)}(x)$ is given 
by [31] :

$$
\begin{aligned}
& T^{(i)}(x)=\frac{l_{i} T_{i-1}-l_{i-1} T_{i}}{l_{i}-l_{i-1}}+\frac{T_{i}-T_{i-1}}{l_{i}-l_{i-1}} x \\
& \text { with } l_{0}=0, T^{i}=T_{i} \text { for } x=l_{i}, i=0,1,2,3
\end{aligned}
$$

\subsection{Boundary conditions}

Outer Boundary Condition : Since the loss of heat from the skin surface due to conduction, convection and radiation to be considered, so the outer boundary condition is [31]

$$
\left.K \frac{\partial T}{\partial x}\right|_{\text {skin surface }}=h\left(T-T_{a}\right)+L E=h\left(T-T_{a}\right)+Q_{e}
$$

where,

$\mathrm{h}=$ combined heat transfer coefficient due to convection and radiation,

$T_{a}=$ atmospheric temperature $\left({ }^{\circ} \mathrm{C}\right)$, and

$\frac{\partial T}{\partial x}=$ the directional derivative of $\mathrm{T}$ along the normal to the skin surface $\left({ }^{\circ} \mathrm{C} / \mathrm{cm}\right)$.

Inner Boundary Condition: The human body maintains its core temperature at a uniform temperature at $37^{\circ} \mathrm{C}$, so the boundary condition condition at the inner boundary is taken as : $T\left(l_{3}\right)=T_{3}=T_{b}=37^{\circ} \mathrm{C}$.

\subsection{Variational form of the model and its solution}

The Euler-Lagrange's equation of the partial differential equation (3) written in one dimensional unsteady case, together with outer boundary condition (4), can be expressed in variational integral form as [31]:

$$
\begin{aligned}
I[T(x, t)] & = \\
& \frac{1}{2} \int_{0}^{l}\left[K\left(\frac{d T}{d x}\right)^{2}+M\left(T_{A}-T\right)^{2}-2 S T+\rho c \frac{\partial T^{2}}{\partial t}\right] d x \\
& +\lambda\left[\frac{1}{2} h\left(T-T_{a}\right)^{2}+Q_{e} T\right]
\end{aligned}
$$

Where,

$$
\begin{array}{r}
l=l_{3}=l_{1}+\left(l_{2}-l_{1}\right)+\left(l_{3}-l_{2}\right) \\
=\text { thickness of SST region }
\end{array}
$$

Here $\lambda=1$ for $0 \leq x \leq l_{1}$ and $\lambda=0$ for otherwise.

Let $I_{1}, I_{2}$ and $I_{3}$ are the element wise integral values for epidermis region, dermis region and subcutaneous tissue respectively. Then the integral $I[T(x, t)]$ in equation 5 can be expressed in terms of finite element discretization as:

$$
\begin{aligned}
I_{1}=\frac{1}{2} \int_{0}^{l_{l}} & {\left[K_{1}\left(\frac{d T^{(1)}}{d x}\right)^{2}+M_{1}\left(T_{A}-T^{(1)}\right)^{2}-2 S_{1} T^{(1)}\right.} \\
& \left.+\rho_{1} c_{1} \frac{\partial T^{(1)^{2}}}{\partial t}\right] d x+\lambda\left[\frac{1}{2} h\left(T-T_{a}\right)^{2}+Q_{e} T\right]
\end{aligned}
$$

$I_{2}=\frac{1}{2} \int_{l_{1}}^{l_{2}}\left[K_{2}\left(\frac{d T^{(2)}}{d x}\right)^{2}+M_{2}\left(T_{A}-T^{(2)}\right)^{2}-2 S_{2} T^{(2)}\right.$ $\left.+\rho_{2} c_{2} \frac{\partial T^{(2)^{2}}}{\partial t}\right] d x$

$$
\begin{aligned}
I_{3}=\frac{1}{2} \int_{l_{2}}^{l_{3}} & {\left[K_{3}\left(\frac{d T^{(3)}}{d x}\right)^{2}+M_{3}\left(T_{A}-T^{(3)}\right)^{2}-2 S_{3} T^{(3)}\right.} \\
& \left.+\rho_{3} c_{3} \frac{\partial T^{(3)^{2}}}{\partial t}\right] d x
\end{aligned}
$$

where,

$K_{i}$ be thermal conductivity rate,

$S_{i}$ be metabolic rate,

$M_{i}=\left(\rho_{b} w_{b} c_{b}\right)_{i}$,

$\rho_{i}$, be density, and

$c_{i}$ be specific heat capacity;

all for $l_{i-1}<x<l_{i}$ with $l_{0}=0$.

On solving the above equations, we get,

$$
\begin{aligned}
I_{1}=A_{1} & +B_{1} T_{0}+D_{1} T_{o}^{2}+E_{1} T_{1}^{2}+F_{1} T_{0} T_{1} \\
& +\alpha_{1} \frac{d}{d t}\left(T_{0}^{2}+T_{1}^{2}+T_{0} T_{1}\right) \\
I_{2}=A_{2} & +B_{2} T_{1}+C_{2} T_{2}+D_{2} T_{1}^{2}+E_{2} T_{2}^{2}+F_{2} T_{1} T_{2} \\
& +\alpha_{2} \frac{d}{d t}\left(T_{1}^{2}+T_{2}^{2}+T_{1} T_{2}\right) \\
I_{3}=A_{3} & +B_{3} T_{2}+C_{3} T_{3}+D_{3} T_{2}^{2}+E_{3} T_{3}^{2}+F_{3} T_{2} T_{3} \\
& +\alpha_{3} \frac{d}{d t}\left(T_{2}^{2}+T_{3}^{2}+T_{2} T_{3}\right)
\end{aligned}
$$

where $A_{k}, B_{k}, C_{k}, D_{k}, E_{k}, F_{k}(k=1,2,3)$ are all constants whose value depends upon physical and physiological parameters $\left(h, T_{a}, L, E, K_{i}, l_{i}, M_{i}, S_{i}, \rho_{i}, c_{i}, m_{i}, T_{b}\right)$ of dermal part [29]. Here $T_{A}=0$ (assumption) in epidermis region and $T_{A}=T_{b}$ otherwise. 
As a next step to finite element method, differentiating $I_{1}, I_{2}$ and $I_{3}$ with respect to $T_{0}, T_{1}$ and $T_{2}$, setting $\frac{d I}{d T_{i}}=0$, for $i=0,1,2 . T_{3}=T_{b}=37^{\circ} \mathrm{C}$ and simplifying gives the matrix equation as

$$
P T+Q \dot{T}=R
$$

where,

$$
\begin{aligned}
& P=\left(\begin{array}{ccc}
2 D_{1} & F_{1} & 0 \\
F_{1} & 2\left(D_{2}+E_{1}\right) & F_{2} \\
0 & F_{2} & 2\left(D_{3}+E_{2}\right)
\end{array}\right) \\
& Q=\left(\begin{array}{ccc}
2 \alpha_{1} & \alpha_{1} & 0 \\
\alpha_{1} & 2\left(\alpha_{1}+\alpha_{2}\right) & \alpha_{2} \\
0 & \alpha_{2} & 2\left(\alpha_{2}+\alpha_{3}\right)
\end{array}\right) \\
& T=\left(\begin{array}{c}
T_{0} \\
T_{1} \\
T_{2}
\end{array}\right) \quad \dot{T}=\left(\begin{array}{c}
\frac{d T_{0}}{d t} \\
\frac{d T_{1}}{d t} \\
\frac{d T_{2}}{d t}
\end{array}\right) \quad R=\left(\begin{array}{c}
-B_{1} \\
-B_{2} \\
-C_{2}-B_{3}-F_{3} T_{3}
\end{array}\right)
\end{aligned}
$$

We use iterative method and the Crank -Nicolson method to solve the equation (6). The Crank -Nicolson method of the above equation (6) can be written as

$$
\left(Q+\frac{\triangle t}{2} P\right) T^{(i+1)}=\left(Q-\frac{\triangle t}{2} P\right) T^{(i)}+\triangle t R .
$$

$\triangle t$ is the initial time interval and $T^{(0)}$ is the initial nodal temperature in $3 \times 1$ matrix form and we may assume the linear equation for $T^{(0)}$ as:

$$
T(x, 0)=T_{0}+\kappa x
$$

$\kappa$ in equation (8) is constant, whose numerical value is determined by taking the known value $T_{3}=T_{b}=37^{\circ} \mathrm{C}$ at $x=l_{3}$.

\section{Result and Discussion}

\subsection{Parameter Values}

For simulation to numerical results of the model, the parameter values are taken as follows:

Table 1: Thickness of skin layers and initial nodal temperatures at $T_{a}=35^{\circ} \mathrm{C}$

\begin{tabular}{|c|c|c|}
\hline $\begin{array}{c}\text { Skin layers } \\
\text { boundary }\end{array}$ & $\begin{array}{c}\text { Depth from } \\
\text { outer surface } \\
(\mathbf{c m})\end{array}$ & $\begin{array}{c}\text { Initial nodal } \\
\text { temperature } \\
\left({ }^{\circ} \mathrm{C}\right)\end{array}$ \\
\hline$l_{0}$ & 0 & $T_{0}=35.20$ \\
\hline$l_{1}$ & 0.10 & $T_{1}=35.44$ \\
\hline$l_{2}$ & 0.50 & $T_{2}=36.40$ \\
\hline$l_{3}$ & 0.75 & $T_{3}=37$ \\
\hline Source & {$[31]$} & eq. 8 \\
\hline
\end{tabular}

Table 2: Layer-wise steady values of $K, S, M, \rho$ and $c$ ([31], [32], [33], [34], [35])

\begin{tabular}{|c|c|c|}
\hline Parameters & Values & Units \\
\hline$K_{1}, K_{2}, K_{3}$ & $0.03,0.045,0.06$ & $\mathrm{cal} / \mathrm{cmmin}^{\circ} \mathrm{C}$ \\
\hline$S_{1}, S_{2}, S_{3}$ & $0, \mathrm{~s}, \mathrm{~s}$ & $\mathrm{cal} / \mathrm{cm}^{3} \mathrm{~min}$ \\
\hline$M_{1}, M_{2}, M_{3}$ & $0, \mathrm{~m}, \mathrm{~m}$ & $\mathrm{cal} / \mathrm{cm}^{3} \mathrm{~min}^{\circ} \mathrm{C}$ \\
\hline$\rho_{1}, \rho_{2}, \rho_{3}$ & $1.05,0.996,1.05$ & $\mathrm{gm} / \mathrm{cm}^{3}$ \\
\hline$c_{1}, c_{2}, c_{3}$ & $0.83,0.38,0.38$ & $\mathrm{cal} / \mathrm{gm}^{\circ} \mathrm{C}$ \\
\hline
\end{tabular}

Table 3: The values of required parameters at $T_{a}=35^{\circ} \mathrm{C}$

\begin{tabular}{|c|c|c|c|}
\hline Parameters & Values & Units & Sources \\
\hline$T_{s}$ & 35.20 & ${ }^{\circ} \mathrm{C}$ & {$[36]$} \\
\hline$P_{v}$ & 41.82 & $\mathrm{mmHg}$ & {$[24]$} \\
\hline$m=m_{b} c_{b}$ & 0.0315 & $\mathrm{cal} / \mathrm{cm}^{3} \mathrm{~min}^{\circ} \mathrm{C}$ & {$[33,34,32]$} \\
\hline$s$ & 0.018 & $\mathrm{cal} / \mathrm{cm}^{3} \mathrm{~min}$ & {$[33,34,32,35]$} \\
\hline$K_{e}$ & $10.17 v_{a}^{0.37}$ & $\mathrm{kcal} / \mathrm{m}^{2} \mathrm{hrmmHg}$ & {$[28,23]$} \\
\hline$v_{a}$ & 0.5 & $\mathrm{~m} / \mathrm{s}$ & assumption \\
\hline
\end{tabular}

Note: $h=0\left(\mathrm{cal} / \mathrm{cm}^{2} \mathrm{~min}^{\circ} \mathrm{C}\right)$ at warm $\left(T_{a}=35^{\circ} \mathrm{C}\right)$ environment $[37,35,32]$.

\subsection{Result and Discussion}

The effect of relative humidity $(\mathrm{RH})$ on temperature distribution in human dermal part at different environmental conditions, based on the above parameters is obtained by solving Eqn. (6) derived in finite element method. The results obtained at different $\mathrm{RH}$ are tabulated and graphed for the comparison of temperatures profile.

As warm conditions, ambient temperature $T_{a}=35^{\circ} \mathrm{C}$ is taken and nodal temperatures on the layers of skin are plotted against different relative humidities from $0 \%$ to $100 \%$ at a constant wind velocity of $0.5 \mathrm{~m} / \mathrm{s}$.

By observing the table 4 and graphs $(2,3)$, it can be noted that change in relative humidity causes the significant fluctuation in nodal temperatures indicating an essential amount of heat loss by evaporation. So it can be concluded that at the warm ambient temperature (below skin temperature), variations in $\mathrm{RH}$ are crucial in human thermo-regulation. This is because sufficient amount of sweating takes place for evaporation to cool down the body in this warm temperature. At such condition evaporation is the major cooling mechanisms for thermal balance. But evaporation can occur if surrounding air can hold water vapor. So higher humidity causes decrease in evaporation rate which restricts cooling mechanism and hence each nodal temperature rises at higher humidities $(80 \%-100 \%)$. 
Table 4: Nodal temperatures, evaporative heat loss rate $Q_{e} \&$ sweat rate $E$ at different $\mathrm{RH}$

\begin{tabular}{|c|c|c|c|c|}
\hline $\begin{array}{l}\mathrm{RH} \\
(\%)\end{array}$ & $\begin{array}{l}\text { Nodal temperatures } \\
{\left[T_{0}: T_{1}: T_{2}\right]_{t=0}\left({ }^{\circ} \mathrm{C}\right)}\end{array}$ & $\begin{array}{l}\text { Nodal temperatures } \\
{\left[T_{0}: T_{1}: T_{2}\right]_{t=30}\left({ }^{\circ} \mathrm{C}\right)}\end{array}$ & $\begin{array}{c}Q_{e} \text { at } t=30 \mathrm{~min} . \\
\left(\mathrm{cal} / \operatorname{min~cm}^{2}\right)\end{array}$ & $\begin{array}{c}E \text { at } t=30 \text { min. } \\
\left(\mathrm{Kg} / \mathrm{hrm}^{2}\right)\end{array}$ \\
\hline 0 & $35.20: 35.44: 36.40$ & $28.17: 30.09: 34.89$ & 0.5770 & 1.0763 \\
\hline 10 & $35.20: 35.44: 36.40$ & $29.05: 30.78: 35.10$ & 0.5200 & 0.9699 \\
\hline 20 & $35.20: 35.44: 36.40$ & $29.93: 31.47: 35.31$ & 0.4629 & 0.8634 \\
\hline 30 & $35.20: 35.44: 36.40$ & $30.81: 32.16: 35.53$ & 0.4058 & 0.7569 \\
\hline 40 & $35.20: 35.44: 36.40$ & $31.69: 32.85: 35.74$ & 0.3487 & 0.6505 \\
\hline 50 & $35.20: 35.44: 36.40$ & $32.56: 33.54: 35.95$ & 0.2917 & 0.5440 \\
\hline 60 & $35.20: 35.44: 36.40$ & $33.45: 34.23: 36.16$ & 0.2346 & 0.4376 \\
\hline 70 & $35.20: 35.44: 36.40$ & $34.32: 34.92: 36.37$ & 0.1775 & 0.3311 \\
\hline 80 & $35.20: 35.44: 36.40$ & $35.20: 35.61: 36.58$ & 0.1204 & 0.2246 \\
\hline 90 & $35.20: 35.44: 36.40$ & $36.08: 36.29: 36.80$ & 0.0633 & 0.1182 \\
\hline 100 & $35.20: 35.44: 36.40$ & $36.96: 36.98: 37.01$ & 0.0063 & 0.0117 \\
\hline
\end{tabular}

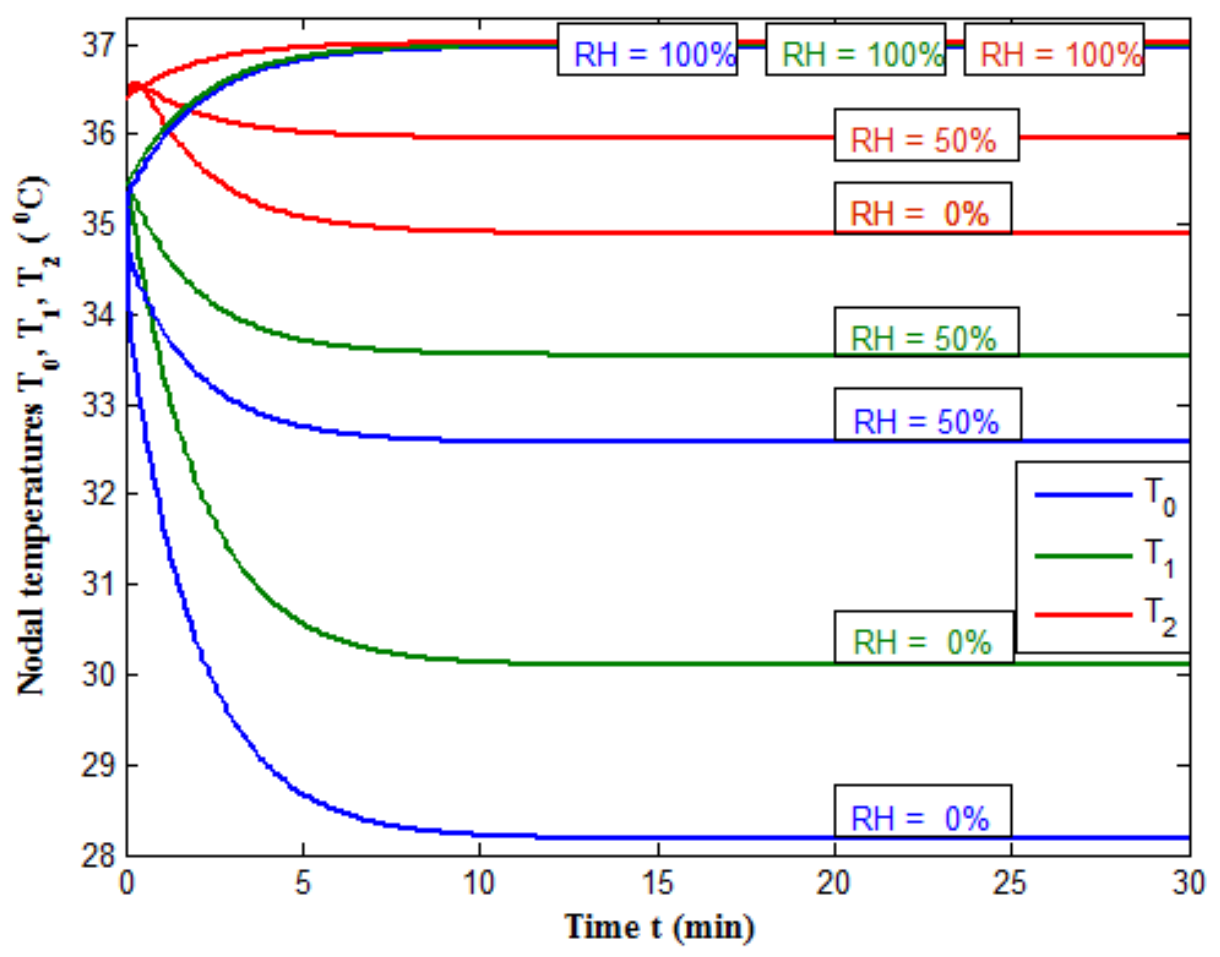

Figure 2: Effect of $\mathrm{RH}$ on nodal temperatures at $T_{a}=35^{\circ} \mathrm{C}$ 

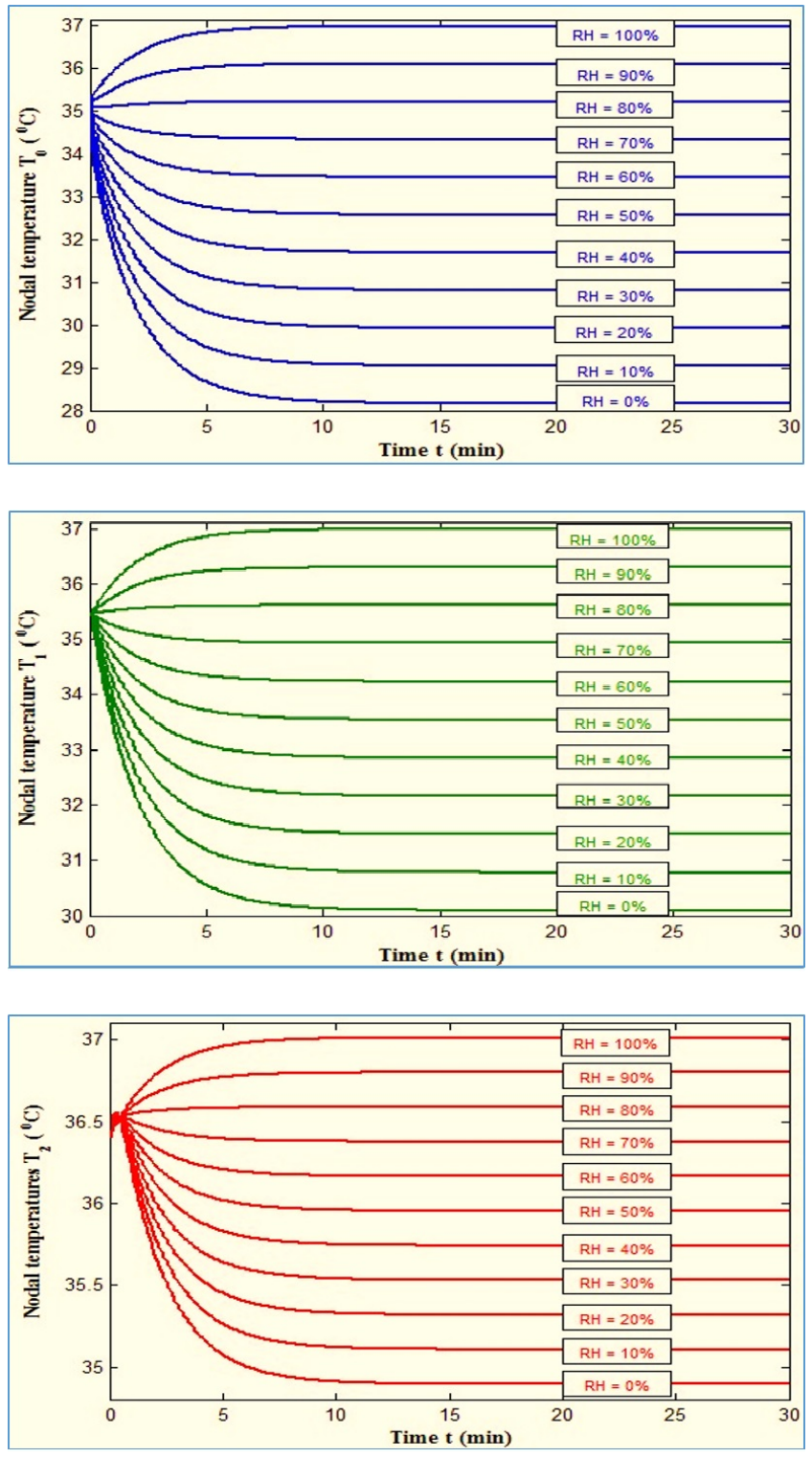

Figure 3: Effect of $\mathrm{RH}$ on individual nodal temperatures at $T_{a}=35^{\circ} \mathrm{C}$

\section{Conclusion}

In the present study, the mathematical model for evaporative heat loss rate during various $\mathrm{RH}$ is formulated, and by implementing it in Pennes' bio-heat equation, a transient one-dimensional mathematical modeling of the human thermoregulatory system has been developed using finite element technique by creating a discretization of the skin into three layers epidermis, dermis and subcutaneous tissue. The numerical solution of the model equation is obtained by the Crank-Nicholson scheme. A Program written in Matlab code is used to determine temperature distribution in each layer.

From the study, it can be concluded that higher humidity reduces the evaporation rate causing an increase in nodal temperatures and converse phenomena occurs for lower humidity. This occurrence is more affecting in warm environmental conditions. In this model, thermal conductivity, metabolic rate, mass flow rate $(\mathrm{m})$ are taken as zero in the epidermis layer, and constant in inner layers. It is assumed that, at the warm environment, major cooling mechanism is evaporation. The model has a limit of the time-independent study of evaporation rate, perfusion rate, metabolic rate and other control parameters. But these parameters can be considered as time dependent to handle realistic situation. The errors in FEM simulated result can be minimized by subdividing the elements into sub-elements. It may increase the mathematical computational complexities, computation cost and time.

This study can be extended in two or three dimensional cases and in more layers. Further study on this topic may help in medical area to suggest and evaluate new treatment strategies for the cases concerning problems on body temperature, sweating effect, heat disorder, skin problem, eye problem, dehydration etc. at different environmental conditions. The effect of humidity on skin temperature at hot and cold conditions may be attentive topics for the researchers concerning outdoor players, athletes, marathon runner etc. and so this study is useful to deal with their thermal imbalance, dehydration and other problems at extremely humid conditions. In military services, army has to suffer from undesirable weather and environment. In this case, this study may suggest an essential plan for his thermal comfort. This model may be effective in skin treatment production like skin creams for different environmental regions. An experimental, extended and advanced study on this topic may help to build defensive strategies on the transmission of viral diseases such as Covid-19 at different humid environments. It gives a good idea to maintain the skin and core temperatures of a patient in the isolation room by adjusting the humidity so that an investigated intentional body temperature should be able to fight against the virus and neutralize them quickly. 


\section{References}

[1] "Thermoregulation," https://www.healthline.com/ health/thermoregulation, 2012, (Accessed on 05/29/2016).

[2] H. S. Sharma, Neurobiology of hyperthermia, 1st ed. Elsevier, 2007, pp. 175-177, 485.

[3] I. Holmér, P.-O. Granberg, and G. Dahlstrom, Cold environments and cold work: Encyclopaedia of Occupational Health and Safety, 4th ed. Part VIGeneral Hazards, Chapter 42: Heat and Cold, ILO, Canada, 1998, ISBN 978-9221092032.

[4] S. Quast and O. Kimberger, The significance of core temperature - Pathophysiology and measurement methods. Dräger Medical GmbH, Germany, 2014, pp. 12-13.

[5] "Nws heat index," www.nws.noaa.gov, National Oceanic and Atmospheric Administration, National Weather Service, USA, (Accessed on 12-23-2016).

[6] J. Mercola, "Effect of low humidity," https://articles.mercola.com/sites/articles/archive/ 2014/01/13/low-humidity-health-effects.aspx, 2014.

[7] G. J. Harper, "Airborne micro-organisms: survival tests with four viruses," Epidemiology \& Infection, vol. 59, no. 4, pp. 479-486, 1961.

[8] G. J. Harper, "The influence of environment on the survival of airborne virus particles in the laboratory," Archiv für die gesamte Virusforschung, vol. 13, no. 1-3, pp. 64-71, 1963.

[9] Y. Sunwoo, C. Chou, J. Takeshita, M. Murakami, and Y. Tochihara, "Physiological and subjective responses to low relative humidity," J. Physiol. Anthropol., vol. 25, no. 1, pp. 7-14, 2006.

[10] M. P. Ward, S. Xiao, and Z. Zhang, "Humidity is a consistent climatic factor contributing to sars-cov2 transmission," Transboundary and Emerging Diseases, vol. 67, no. 6, pp. 3069-3074, 2020.

[11] A. Sandoiu, "How humidity may affect covid-19 outcome," https: //www.medicalnewstoday.com/articles/ how-humidity-may-affect-covid-19-outcome, April 2020.
[12] V. Bradshaw, The building environment: Active and passive control systems, 6th ed. John Wiley \& Sons, 2006, ISBN 978-0-471-68965-2.

[13] G. W. Mack and E. R. Nadel, "Body fluid balance during heat stress in humans," Comprehensive Physiology, pp. 187-214, 2010.

[14] D. W. Pepper and J. C. Heinrich, The Finite Element Method, Basic Concepts and Applications, 2nd ed. CRC Press, Taylor and Frabcis Group, 2006, iSBN 1-59169-027-7.

[15] J. N. Reddy, An introduction to the finite element method, 2nd ed. Tata McGraw Hill, New Delhi, 1993.

[16] S. S. Rao, The finite element method in Engineering. Elsevier, 2009.

[17] R. D. Cook, D. S. Malkus, M. E. Plesha, and R. J. Witt, Concepts and Applications of finite element Analysis, 4th ed. John Willey \& Sons (Asia), 2004, ISBN:978-81-265-1336-9.

[18] R. Pratap, Getting Started with MATLAB 7: A Quick Introduction for Scientists and Engineers. Oxford University Press, USA, 2005, ISBN:0195179374.

[19] Y. K. Singh and B. B. Chaudhuri, Matlab programming. PHI Learning, New Delhi, 2010, ISBN: 978-81-203-3081-8.

[20] B. R. Hunt, R. L. Lipsman, and J. M. Rosenberg, A Guide to MATLAB for Beginners and Experienced Users. Cambridge University Press, Cambridge, New York, 2001, ISBN: 978-0-521-54086-5.

[21] P. I. Kattan, MATLAB guide to finite elements: an interactive approach, 2nd ed. Springer, 2006.

[22] G. Havenith, "Temperature regulation, heat balance and climatic stress," in Extreme weather events and public health responses. Springer, 2005, pp. 69-80.

[23] E. D. Yildirim, "A mathematical model of the human thermal system," M.Sc. Thesis, Graduate School of Engineering and Sciences of Izmir Institute of Technology, Izmir, Turkey, 2005.

[24] K. Atkins and M. Thompson, "A spreadsheet for partitional calorimetry," Sportscience, vol. 4, no. 3, 2000 . 
[25] D. O. Cooney, Bio-medical engineering principles. Marcel Dekker Inc., New York, 1976, ISBN: 08247-6347-5.

[26] T. Inouye, F. K. Hick, R. W. Keeton, J. Losch, and N. Glickman, "Effect of relative humidity on heat loss of men exposed to environments of 80,76 and 72 F," ASHVE Transactions, vol. 59, pp. 329-346, 1953.

[27] P. W. Ryan, "Heat production of college-age persons at four levels of activity and their corresponding thermal comfort condition," M.Sc. Thesis, Department of Mechanical Engineering, Kansas State University, Manhattan, Kansas, 1967.

[28] J. Clifford, D. M. Kerslake, and J. Waddell, "The effect of wind speed on maximum evaporative capacity in man," The Journal of physiology, vol. 147, no. 2, p. 253, 1959.

[29] S. H. Subedi, "A mathematical study of effect of humidity on skin temperature," M.Phil. Thesis, Department of Natural Sciences (Mathematics), School of Science, Kathmandu University, Nepal, 2017.

[30] H. H. Pennes, "Analysis of tissue and arterial blood temperatures in the resting human forearm," Journal of applied physiology, vol. 1, no. 2, pp. 93-122, 1948.

[31] D. B. Gurung, "Mathematical study of abnormal thermoregulation in human dermal parts," P.hd Thesis, Department of Natural Sciences (Mathematics), School of Science, Kathmandu University, Nepal, 2007.

[32] D. B. Gurung, V. P. Saxena, and P. R. Adhikary, "Fem approach to one dimensional unsteady state temperature distribution in human dermal parts with quadratic shape function," Journal of Applied maths \& Informatics, vol. 27, pp. 301-313, 2009.

[33] M. Jain and M. Shakya, "Study of temperature variation in human peripheral region during wound healing process due to plastic surgery," Applied Mathematical Sciences, vol. 3, no. 54, pp. 26512662, 2009.

[34] A. Makrariya and N. Adlakha, "Two-dimensional finite element model of temperature distribution in dermal tissues of extended spherical organs of a human body," International Journal of Biomathematics, vol. 6, no. 01, pp. 1250065-1 to 15, 2013.

[35] Y. Shukla, "A mathematical approach to study temperature regulation of human body due to different arterial blood temperature," IOSR Journal of Mathematics (IOSR-JM), vol. 10, no. 2, pp. 1-5, 2014, ISSN:2319-765.

[36] I. A. Strigo, F. Carli, and M. C. Bushnell, "Effect of ambient temperature on human pain and temperature perception," Anesthesiology:@2000 American Society of Anesthesiologists, Inc., vol. 92, pp. 699-707, 2000.

[37] D. B. Gurung, "Two dimensional temperature distribution model in human dermal region exposed at low ambient temperatures with air flow," Kathmandu University Journal of Science, Engineering and Technology, vol. 8, pp. 11-24, 2012. 